\title{
Leveraging Social Media in New Product Development: Organisational Learning Processes, Mechanisms and Evidence from China
}

\begin{tabular}{|r|l|}
\hline Journal: & International Journal of Operations and Production Management \\
\hline Manuscript ID & IJOPM-04-2019-0318.R3 \\
\hline Manuscript Type: & Research Paper \\
\hline Keywords: & $\begin{array}{l}\text { Social media, New product development, organisational learning, Case } \\
\text { study, China }\end{array}$ \\
\hline \multicolumn{2}{|l}{} \\
\hline
\end{tabular}




\title{
Leveraging Social Media in New Product Development: Organisational Learning Processes, Mechanisms and Evidence from China
}

\begin{abstract}
Purpose - The main purpose of this paper is to investigate how social media can provide important platforms to facilitate organisational learning and innovation in new product development (NPD) process.
\end{abstract}

Design/methodology/approach - Using a multiple case-study approach, this study assesses qualitative data collected via 56 interviews from 13 world-leading Chinese companies in the high-technology industry.

Findings - The study identified three distinct types of organisational learning mechanisms for firms to extract potential innovation inherent in social media. It further determined various organisational enablers that facilitate the connections between these mechanisms and NPD performance.

Research limitations/implications - This research contributes to the emerging literature on digital product development and organisational learning. The cases were conducted in the Chinese context, hence, the results may not be fully generalisable to other organisations, industries and countries without appropriate re-contextualisation.

Practical implications - The empirical evidence showcases the various mechanisms adopted by managers in different NPD phases. It identifies several technological and organisational adaptations that managers can apply to smartly scale their social presence and facilitate NPD.

Originality/value - Despite the exponential growth of social media use in identifying and interacting with external stakeholders, managerial practice and academic research have paid little attention to how social media can be leveraged for NPD. The value of this research comes from applying a qualitative method to gain in-depth insights into the mechanisms for leveraging social media to facilitate innovation in NPD.

Keywords: social media, new product development, organisational learning, case study, China 


\section{Introduction}

Successful new product development (NPD) requires effective exploration and exploitation of different kinds of knowledge from various sources (Stevens and Dimitriadis, 2004; Nguyen et al., 2015). However, for many companies, this process is not straightforward, given the considerable levels of complexity with which they are confronted, both in terms of technical feasibility and market competitiveness (Roberts and Candi, 2014; Zhu et al., 2017; Ramanathan et al., 2017). This is especially true in NPD, where customers increasingly demand speed delivery, better quality and lower price (Mount and Martinez, 2014; Neeley and Leonardi, 2018). As a consequence, the understanding of how companies can effectively manage knowledge from different sources and develop new products to meet market needs is essential.

Use of social media to identify, collaborate and interact with external stakeholders has gained popularity over the past decades (Culnan et al., 2010; Lam et al., 2016; Neeley and Leonardi, 2018). According to Barnes and Pavao (2017), more than $98 \%$ of Fortune 500 companies have implemented a range of social media applications (e.g. LinkedIn, Twitter, Facebook and YouTube) for internal purposes or to interact with customers, suppliers or partners. The improved media richness and outreach provided by these applications support many-to-many interactions and contribute to effective NPD (Sethi et al., 2003; Mount and Martinez, 2014; Huang et al., 2017). Nevertheless, while there is a general understanding of the relationship between social media applications and NPD performance (Roberts and Candi, 2014; Roberts et al., 2016), current research offers little insight into how these processes actually work and how they can be organised effectively throughout the entire NPD process (Sethi et al., 2003; Franke and Piller, 2011; Roberts and Candi, 2014; Felix et al., 2017).

Organisational learning theory suggests that different approaches to knowledge management exist (Cook and Brown, 1999; Neeley and Leonardi, 2018), but these have not been studied in the context of NPD. NPD can be seen as an organisational learning process to exploit and acquire business opportunities and new knowledge (Atuahene-Gima and Murray, 2007); thus, knowledge is a source of sustainable competitive advantage (Nguyen et al., 2015). Bharati et al. (2015) point out that the use of social media for better knowledge management can significantly improve product effectiveness, and He et al. (2017) encourage studies to pay particular attention to the micro-levels of knowledge management by integrating such processes into social media initiatives. Therefore, it is imperative that the use of social media 
be regarded as an organisational learning and creativity process for knowledge management (Kane and Alavi, 2007). This article, therefore, seeks to investigate how companies develop new products through organisational learning and knowledge management. More specifically, it intends to study how social media can facilitate innovation throughout the entire NPD process.

This study investigates the research question using a case-study approach. The findings offer qualitative evidence of usable mechanisms to leverage social media in enhancing NPD performance from 13 world-leading Chinese companies. Moreover, the findings also reveal a previously unidentified learning process, entailing the cost-effective and time-efficient pursuit of a cyclic process of organisational learning through exploration and exploitation. The findings show that while social media is initially instrumental in facilitating information search and knowledge acquisition, the success of product ideation still heavily depends on firms' capacity to actively seek distinctive or qualitative knowledge. Additionally, the ability to acquire and identify external resources and knowledge through social media is crucial for the innovativeness and success of product R\&D. Likewise, social media can act as important platforms for reflective learning and knowledge transformation during the product testing and launch process.

This research extends organisational learning and knowledge management theories by demonstrating that social media not only intensifies firms' volume of information and knowledge, but also helps to leverage different forms of learning activities throughout the NPD process. Particularly, the study responds to recent calls for a more integrated perspective on the use of social media in innovation and knowledge management (Lam et al., 2016; Ramanathan et al., 2017; Cheng et al., 2018). It suggests that NPD can be organised in a resource-effective way through various social media mechanisms and knowledge learning strategies. Besides, the identification of how social media acts as the leverage platform for NPD adds to the organisational learning and knowledge management literature. This study is also one of the first to illustrate how organisational learning and knowledge management can be translated into innovation mechanisms via social media. As this approach combines exploration with efficient exploitation of existing knowledge, it also reconciles the apparent juxtaposition between 'knowledge searching' and 'knowledge in-action' - an important transformation from product ideation to successful commercialisation (Daft et al., 1988; Nag and Gioia, 2012). While social media has traditionally been conceived as implying the random collection of 
various sources of information (Franke and Piller, 2004; Sigala, 2012; Mount and Martinez, 2014), these findings reveal how social media provides the capabilities for enhancing learning through the three mechanisms of NPD: dynamic searching for product ideation, collective learning for product R\&D and knowledge in-action for product testing and launch.

\section{Theoretical Background}

To study the use of social media in NPD, this paper relies on two main literature streams: social media in NPD and organisational learning. The literature on the use of social media in NPD formed the initial basis for this study, while the relevance of organisational learning processes for knowledge management emerged from the case-study analysis. For clarity, both are discussed here.

\subsection{Social Media in NPD}

Social media refers to "a group of Internet-based applications that build on the ideological and technological foundations of Web 2.0, and that allow the creation and exchange of User Generated Content" (Kaplan and Haenlein, 2010, p. 61). While there is broad agreement on the need for applying social media in NPD, there is less convergence on how this should be realised. An analysis of the literature revealed that social media can be used and implemented differently in NPD. As shown in Table 1, the use of social media falls into three NPD phases: a) product ideation and design - the initial phase centred on the creation and recognition of novel ideas, opportunities and new product concepts (Cooper, 2016; Zhu et al., 2017); b) product $\mathrm{R} \& \mathrm{D}$ - innovative activities undertaken by companies in developing new services/products or improving existing services/products (Nambisan, 2002; Huang et al., 2017); and c) product testing and launch-a process of measuring the properties of performance of a product and making it available on the market (Kim and Wilemon, 2002). 
Table 1: Research relating to social media in NPD

\begin{tabular}{|c|c|c|}
\hline $\begin{array}{c}\text { The Use of Social Media } \\
\text { in NPD }\end{array}$ & Key Benefits & Literature Support* \\
\hline $\begin{array}{l}\text { Product ideation and } \\
\text { design }\end{array}$ & $\begin{array}{l}\text { - } \text { Generate new ideas } \\
\text { - Reduce the risk of adopting wrong } \\
\text { product concepts } \\
\text { - } \text { Allow rapid speed of communication } \\
\text { - Ensure customer base growth }\end{array}$ & $\begin{array}{l}1,2,3,4,5,6,8,9,11, \\
12,13,14,15,16,17,18, \\
19,20,21,22,23,24,\end{array}$ \\
\hline Product R\&D & $\begin{array}{l}\text { - Improve innovativeness and efficiency } \\
\text { - } \text { Reduce costs } \\
\text { - Ensure better adoption of products }\end{array}$ & $\begin{array}{l}2,3,4,5,7,9,10,11,12, \\
13,14,15,17,20,21, \\
22,23,24,\end{array}$ \\
\hline $\begin{array}{l}\text { Product testing and } \\
\text { launch }\end{array}$ & $\begin{array}{l}\text { - } \text { Receive feedback rapidly } \\
\text { - } \text { Reduce product rework } \\
\text { - } \text { Create more opportunities for product } \\
\text { repositioning } \\
\text { - Improve bug corrections } \\
\text { - } \\
\text { Reduce time and costs }\end{array}$ & $\begin{array}{l}1,2,3,4,5,7,9,11,12 \\
13,15,17,19,21,23,25\end{array}$ \\
\hline
\end{tabular}

Notes. 1. Aral and Walker (2011); 2. Cooper (2016); 3. Mount and Martinez (2014); 4. Hanna et al. (2011); 5. Roberts and Candi (2014); 6. Lüthje and Herstatt (2004); 7. Roberts et al. (2016); 8. Kim and Wilemon (2002); 9. Tan and Zhan (2017); 10. Sethi et al. (2003); 11. Culnan et al. (2010); 12. Zhan et al. (2016); 13. Nambisan (2002); 14. Sigala (2012); 15. Hagel and Brown (2011); 16. Franke and Piller (2004); 17. Mangold and Faulds (2009); 18. Decker et al. (2005); 19. Nambisan and Baron (2010); 20. Zhu et al. (2017); 21. Piller et al. (2011); 22. Hoyer et al. (2010); 23. Du et al. (2016); 24. He et al. (2017); 25. Felix et al. (2017).

The use of social media for product ideation and design. In the literature on product development, the most-recognised benefit of using social media is that of providing value and knowledge to organisations (Aral and Walker, 2011; Cooper, 2016; Neeley and Leonardi, 2018). In fact, the use of social media for product ideation and design is relatively well developed in the NPD literature (Lüthje and Herstatt, 2004; Mount and Martinez, 2014). While many studies have noted that social media plays a valuable role in product ideation and design to develop innovative products, others have criticised using social media to involve customers in product ideation and design, arguing that this can result in imitative and unimaginative products (Roberts et al., 2016). It is now recognised that the use of social media differs with the levels of technology readiness and alignment of product development strategies to current customer requirements (Culnan et al., 2010; Chiu et al., 2012; Roberts et al., 2016). Research has demonstrated that successful companies tend to implement different social media applications for their product ideation and design (Franke and Piller, 2004; Aral and Walker, 2011; Zhu et al., 2017). For example, Lenovo Social Champions and Starbucks Ideas are 
popular social media platforms on which users can not only share their comments, but also create new content, with each other or the company's NPD teams.

The use of social media for product $R \& D$. Social media plays an essential role in product $R \& D$. It supports activities such as the prioritisation and design of product prototypes, the validation of product features, the establishment of development-process metrics and the identification of product-interface requirements (Sigala, 2012; Piller et al., 2011; Cooper, 2016). This use of social media is consistent with open forms of NPD (West et al., 2014), virtual communities and online platforms (Du et al., 2016). Also, it is highly pertinent in the era of 'big data', in which emphasis is placed on sharing and extracting knowledge and perceptions from external stakeholders (Manyika et al., 2013; Zhan et al., 2016). By engaging in such interaction, the company's knowledge is enhanced, and the information generated may be embedded in product R\&D (Hoyer et al., 2010; Roberts et al., 2016). This can lead to new products that are more valued by consumers and closer to their requirements than products created by companies in isolation (Kim and Wilemon, 2002; Cooper, 2016). For example, Polyvore is a communitypowered social commerce platform owned by $\mathrm{SSENSE}^{1}$ that focuses on collaborative NPD with social media communities. The public send ideas to Polyvore, who then creates prototypes, which are subsequently voted on by the members of different social media communities. This process allows the rapid development of new products that have strong market attractiveness.

The use of social media for product testing and launch. As product testing and launch is the final and very costly phase of the process of NPD (Roberts and Candi, 2014), companies that are proficient in establishing social media strategies can affect consumer perceptions and therefore increase the likelihood of new product acceptance and successful launch (Du et al., 2016; Roberts et al., 2016). Research has identified the remarkably productive use of social media for product testing and launch (Ramanathan et al., 2017; Tan and Zhan, 2017). Roberts et al. (2016) note that by involving a variety of consumers through social media in product testing, companies can acquire in-depth understanding of how their new product fits with different types of consumers. In addition, using social media in product testing allows companies to identify product defects early, and reduce costly rework and redesign (Felix et al., 2017). For example, many companies in the high-tech industry (e.g., IBM, Tencent and

\footnotetext{
${ }^{1}$ SSENSE is a pioneering international fashion platform. It integrates its programme with a variety of social media channels and utilises social media data and reporting capabilities to produce a more data-driven product.
} 
Lenovo) have applied social media to connect with its end-users in their beta product testing, a process that allows companies to minimise investment in internal product testing procedures (Chiu et al., 2012). During a product's launch, social media can also offer practical and innovative ways of interacting with a wide range of consumers, facilitating communication in a way that traditional methods cannot provide and allowing companies to become close to their target markets (Hagel and Brown, 2011; Cooper, 2016).

\subsection{Social Media in Organisational Learning}

In general, NPD is one part of the organisational learning process through which companies try to solve problems and achieve competitive advantages (Stevens and Dimitriadis, 2004). Rojo et al. (2018) point out that organisational learning is a dynamic process of generating new knowledge and applying to where it is required, leading to the generation of new knowledge for later use and integration. Therefore, social media can be regarded as high levels of mediarich modalities for collaboration, offering companies a powerful means of knowledge acquisition and integration that can be implemented in organisational learning (Nguyen et al., 2015). According to Hemsley and Mason (2013), managers leverage social media to search for new knowledge, and synthesise multiple sources of knowledge into the body of existing knowledge through integration, which then guides action. This is in line with Daft et al.'s (1988) arguments that companies differ systematically from each other in their patterns of searching, integration and action, pointing to the need to develop an in-depth understanding of relationships among knowledge acquisition, integration and action.

Social media for knowledge acquisition. A related but distinct stream of studies stresses the significance of social media as a key knowledge search/acquisition behaviour in NPD (Koskinen and Vanharanta, 2002; Robert et al., 2008; Hemsley and Mason, 2013). This paper defines knowledge acquisition from social media as the capability to search for critical and insightful knowledge emerging from social media necessary to a company's NPD projects (Robert et al., 2008). Studies illustrate that managers of successful companies apply social media more widely for knowledge acquisition in NPD (Chiu et al., 2012; Barnes and Pavao, 2017), and these managers possess 'information flexibility', adopting different social media initiatives given the perceived uncertainty of external environments (Roberts and Candi, 2014; Zhu et al., 2017). Leonardi (2015) argues the need to expand the conception of social media beyond the narrow view of formalised information-gathering activities. Thus, it is critical to 
study whether differences in managers' social media search patterns result in the acquisition of different types of knowledge.

Social media for knowledge integration. As a vital part of knowledge management, knowledge integration refers to the process of synthesising multiple specialised streams of knowledge into situation-specific systemic knowledge (Kane and Alavi, 2007). Robert et al. (2008) point out that the essential source of competitive advantage comes from knowledge integration rather than knowledge itself. According to McKinsey (2012), companies are incorporating social media inside their operations to enhance communication and R\&D collaboration. While research has offered exploratory insights into social media's impact on knowledge management (Leonardi, 2015; Hemsley and Mason, 2013), the influence of social media on knowledge integration has been overlooked. Most importantly, studies emphasise the significance of investigating how social media can be leveraged for knowledge integration in NPD.

Social media for knowledge-in-action. So far, empirical study on how social media generates competitive advantages have mainly emphasised the quality and quantity of knowledge created by companies (Koskinen and Vanharanta, 2002; Bharati et al., 2015; He et al., 2017). This 'possession' perspective of knowledge has been further enhanced by the perception that knowledge is an organisational asset in use rather than something located in dispersed units in a company (Nag et al., 2007). Based on early studies, researchers have identified a practical perspective on knowledge wherein it is regarded as embedded and integrated into the practice of a company's daily work (Pentland, 1992; Nag et al., 2007; Nag and Gioia, 2012). In this way, social media can be used as a kind of knowledge application to enable companies to communicate information with specific experts or broadcast information to the entire company. Accordingly, this research builds on calls for more empirical case studies that focus not only on the body of knowledge that a company acquires, integrates and transfers, but on methods via which companies can dynamically conduct to support innovation (Cook and Brown, 1999).

In essence, the literature review provided insights into the use of social media in NPD and organisational learning. These are separate streams of research, and this is perhaps the main reason why, to date, no study has provided holistic insights into how managers can leverage social media for organisational learning as well as facilitating innovation throughout the entire NPD process. These streams provide a starting point for the data collection and analysis of this study. 


\section{Methodology}

\subsection{The Context of the Study}

Chinese companies were chosen as the research population, for three reasons. Firstly, according to Internet World Stats (2018), China has the world's largest internet user base-772 million people, more than double the 312 million users in the US - and the world's most dynamic environment for social media. Additionally, China's online users spend over $40 \%$ of their time on social media, and this percentage continues to increase rapidly (Chiu et al., 2012). As a result, Chinese companies are operating in an increasingly demanding consumer market environment that is catalysing the use of social media in product development (Woetzel et al., 2015), as the country attempts to meet its 'innovation imperative'. Secondly, several Chinese companies (e.g., Xiaomi, and Tencent) have been aggressively experimenting with social media intensive, novel innovation models that have demonstrably facilitated and achieved great benefits in their NPD activities (Williamson and Yin, 2014). In fact, the country's social media activities in this area have been so impressive that McKinsey \& Company (Woetzel et al., 2015), the global consulting firm, has specifically called for other countries to take note of and learn from the Chinese model of social product development. Thirdly, most research into NPD has focused on Western economies and companies (Roberts and Candi, 2014). Because of the size and rapid growth rate of its economy, China has emerged as the world's largest social media market, and this market differs from those in Western countries (Chiu et al., 2012). For example, the social media sector in China is very local and fragmented (e.g. there is no Facebook, Twitter or YouTube). Each social media platform has its own local players, for example, Sina Blog (a Chinese version of Twitter), Tencent WeChat (the Chinese WhatsApp), Youku (the Chinese equivalent of YouTube), but with more users and improved features. Therefore, the specific nuances of how social media intensive NPD occurs within the Chinese context are extremely relevant on both a practical and theoretical level for those attempting to engage Chinese consumers. Nonetheless, examination of these nuances has been largely overlooked in the literature. Thus, this study helps to fill this knowledge gap.

\subsection{Research Design and Data Sources}

This research identified the case-study approach as the most suitable methodology because of the research objective and the context-specific nature of the phenomenon being explored 
(Meredith, 1998; Yin, 2011). It applied a purposeful sampling method to select case companies; specifically, Clarivate Analytics (clarivate.com) was consulted to identify an initial pool of companies. As a global information-led company that focuses on the innovation development of global enterprises, Clarivate Analytics maintains a 'Top 100 Chinese Innovators' list. These companies are assessed according to their compliance with four criteria: volume - a certain volume of inventions in the past five years; success-the novelty of the innovation; globalisation - the value an organisation places on an invention by protecting it across the major world markets; and influence-impact of an organisation's innovations (Clarivate Analytics, 2017).

Initially, 21 companies were identified from the 'Top 100 Chinese Innovators' list based on three criteria: fast-cycle industry, social media engagement in NPD and evidence of different NPD phases. Companies in fast-cycle industries, in which product life cycles are short, often lasting several years or less (Brexendorf et al., 2015), were targeted first. Most companies in fast-cycle industries are high-tech or electronics companies, and important drivers of innovation and economic growth (Woetzel et al., 2015). It was expected that these companies would be more socially active and proficient at using social media in NPD. The second criterion was the presence of social media engagement and applications to facilitate NPD. The third criterion was evidence of projects focused on different NPD phases (because this research examines the entire NPD process). In particular, companies' archival information and reports, including business reports and news articles, were evaluated to determine whether they were committed to and proactive in social media and NPD.

Starting from July 2017, we adopted a retrospective approach to get familiar with the companies identified (Miller et al., 1997). Pilot tests were conducted with senior managers from the Chinese offices and headquarters of these companies to evaluate their eligibility based on the sampling method. During this process, eight companies were excluded, because either their social media initiatives were too limited (e.g., mainly focused on marketing) or they were unable to grant access to confidential information. Ultimately, 13 companies were identified to participate in this study. All companies extensively used social media to re-engineer their R\&D and NPD, but differed in their NPD directions; namely, product ideation and design, R\&D, and product testing and launch. 


\subsection{Data Collection and Analysis}

It is worth noting that all 13 chosen companies are very large corporations operating globally or nationally. The research studied specific innovation projects within the case companies. According to Tidd and Bessant (2018), conducting innovation research at the project level allows researchers to reflect on their own experience during the whole innovation process and become a part of the project. The study's semi-structured interview protocol began with general questions and then focused particularly on the mechanisms of social media use in NPD and expertise in developing these mechanisms for competitive advantage. Data was collected between March 2018 and September 2019. In total, 56 in-depth semi-structured interviews were conducted with executives from 13 case companies. Almost all interviewees were senior managers performing important roles in the NPD activities, but other employees identified by senior managers as playing key roles in successfully using social media in NPD were also interviewed. Table 2 summarises the data collection methodology, including visiting operations sites of all companies, participating in internal workshops and meetings, gathering company newsletters and annual reports, and observing the teams using social media in NPD. According to Eisenhardt (1989), onsite observations can offer insights into everyday working activities because they shift the focus to the direct study of contextualised actions. Meanwhile, archival data were used primarily to generate a deeper understanding of the strategic impacts of social media on NPD and to verify empirical findings to provide strong support for the results developed.

Table 2: Summary of interviews undertaken in the research

\begin{tabular}{|c|c|c|c|c|}
\hline Cases & Main NPD phase & Interviewee's formal position & $\begin{array}{l}\text { Number of } \\
\text { interviews }\end{array}$ & Mode \\
\hline A & $\begin{array}{c}\text { Product ideation and } \\
\text { design }\end{array}$ & $\begin{array}{l}\text { Deputy CEO; vice general manager; } \\
\text { head of internet and mobile service } \\
\text { development; senior customer insight } \\
\text { analysts }\end{array}$ & 6 & $\begin{array}{l}\text { Onsite; } \\
\text { telephone }\end{array}$ \\
\hline B & Product R\&D & $\begin{array}{l}\text { CIO; senior managers of open } \\
\text { innovation R\&D; head of innovation }\end{array}$ & & $\begin{array}{l}\text { Onsite; } \\
\text { telephone }\end{array}$ \\
\hline $\mathrm{C}$ & $\begin{array}{l}\text { Product testing and } \\
\text { launch }\end{array}$ & $\begin{array}{l}\text { vice general manager; head of data and } \\
\text { analytics; senior technology managers; } \\
\text { R\&D senior managers }\end{array}$ & & $\begin{array}{l}\text { Onsite; } \\
\text { telephone }\end{array}$ \\
\hline $\mathrm{D}$ & Product R\&D & $\begin{array}{l}\text { Head of IT department; professoriate } \\
\text { senior engineers; R\&D project } \\
\text { managers }\end{array}$ & 5 & $\begin{array}{l}\text { Onsite; } \\
\text { telephone }\end{array}$ \\
\hline $\mathrm{E}$ & Product R\&D & $\begin{array}{l}\text { Previous head of the } R \& D \text { department; } \\
\text { senior operations managers }\end{array}$ & 3 & Onsite \\
\hline $\mathrm{F}$ & $\begin{array}{l}\text { Product testing and } \\
\text { launch }\end{array}$ & $\begin{array}{l}\text { VP technology; senior IT engineers; } \\
\text { R\&D senior manager }\end{array}$ & 4 & Onsite \\
\hline G & Product R\&D & $\begin{array}{l}\text { CIO; senior IT project manager; senior } \\
\text { project managers }\end{array}$ & 4 & $\begin{array}{l}\text { Onsite; } \\
\text { telephone }\end{array}$ \\
\hline
\end{tabular}


$\mathrm{H} \quad$ Product ideation and design

I Product ideation and design

Product testing and launch

K Product R\&D

L Product ideation and design

M Product testing and launch
R\&D director; technical director; senior data analyst; senior R\&D team members

VP production; open innovation senior manager

Head of R\&D department; senior IT managers

Process innovation director; $R \& D$ project leader

CIO; R\&D director; senior production manager VP technology; open innovation project managers; R\&D senior manager

Total:

$$
\text { manager }
$$

Onsite;
telephone

56

Note. One interview was with a previous head of the R\&D department from Case E, who had very recently left the company after overseeing several social product development projects.

Following Miles and Huberman's (1984) suggestions for analysing data from multiple cases, data analysis was conducted in two steps. First, each case was analysed in detail using withincase analysis. Adopting the theme analysis and categorisation techniques, each interview was coded separately according to categories derived from the interviewees' quotations (i.e. firstorder categories). Second, the cases were compared through cross-site analysis to identify emergent categories from different cases. Specifically, each interview was checked many times to identify differences and similarities among interviewees. The constant-comparison method was adopted across multiple interviewees to determine concept patterns (Strauss and Corbin, 1994). Similar codes were identified and allocated to the same first-order categories. To reach theoretical saturation (Strauss and Corbin, 1994), interviewing and data analysis was continued until no further distinct codes or shared patterns among interviewees emerged. Concurrently with the establishment of the first-order categories, relationships among the categories that could result in the formulation of second-order themes - theoretically distinct concepts induced by the researcher and developed at a more abstract level-were identified. The formulated second-order themes were then integrated into aggregate mechanisms, which led to developing a theoretical framework that integrated the different ideas captured from the data. 


\section{Findings and Propositions: Insights from NPD projects illustrating three different types of mechanisms}

The analysis indicates that successful Chinese companies operating under similar exogenous conditions display distinct variations in how they used social media in NPD. The emergent theoretical model comprises various mechanisms under the entire process of the three core NPD phases: dynamic scanning for ideation, collective learning for R\&D and a fast-launchand-improve cycle for testing and launch. Figure 1 presents the data structure, including the first-order categories (categories derived from the interviewees' quotations) and second-order themes (theoretically distinct concepts induced by the researcher) that led to the development of the aggregate mechanisms underlying the three NPD phases. These identified data structures represent the content of senior managers' interpretive frameworks on how social media can be leveraged in NPD. A summary of cross-case synthesis is shown in Appendices A, B and C. According to Eisenhardt (1989) and Nag et al. (2007), a developing theoretical framework based on grounded theory approaches such as constant comparison and data reduction must specify not only constituent concepts, but also connections among the constituent concepts to explain or describe a phenomenon. Therefore, following the approaches of systematic combining, this paper identifies which aspects of social media usage pertain to a specific context and can be generalised theoretically (Hullova et al., 2019). These are displayed in the form of six propositions, which lead to directions for future study. 
- Spend quite a bit of time searching for new concepts

- Monitor and track events (e.g. operational and NPD performance) on social media closely

- Look for new ways to integrate social media in ideation

- Harvest values from many different social media platforms

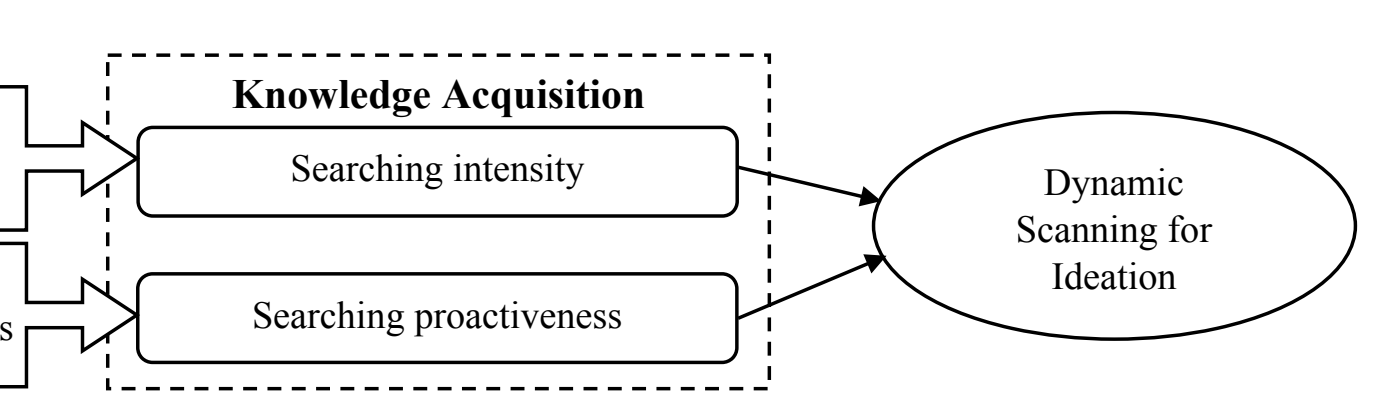

- Crowd collaborations on social media is important

- Collect and publish creative content across different social media platforms

- Assessment of product novelty in NPD

- Adopt social media to blend disparate solutions in new and novel ways

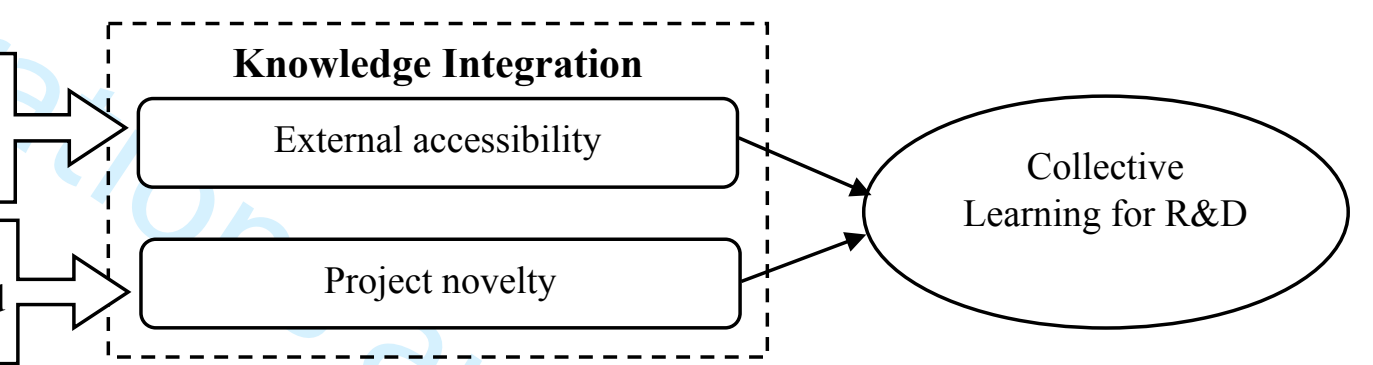

- Use social media for issue detection, assessment, reporting and verification

- A trial launch of new products on social media

- Extract knowledge from social media as inputs to facilitate product modification and launch

- Analyse issues to generate new insights/understanding

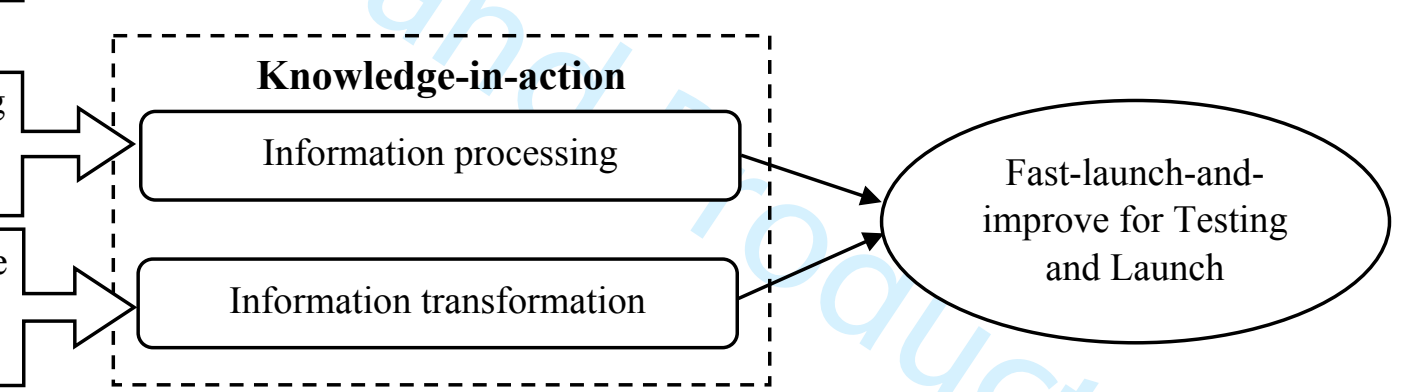

Figure 1: Data structure 


\subsection{Dynamic Scanning for Ideation}

The findings indicate a distinct ability of the cases to generate excellent product ideas and designs addressing seemingly untapped areas of the existing market. In particular, social media was associated with differences in both the character and amount of searching focused on acquiring knowledge in product ideation. Consistent with existing literature, the analysis confirmed the prevalence and significance of the 'intensity' with which searching was implemented (Tóth et al., 2019). A second mode of searching also appeared from the analysisthe extent to which managers apply social media resourcefully and proactively search for information. Thus, the findings expand the basic searching concept into two distinct forms: searching intensity and searching proactiveness.

Searching intensity refers to the number of social media initiatives implemented in a specific domain, normally operationalised as the amount of time and energy managers devote to knowledge acquisition and searching for new product ideas. Comparisons among the cases indicate that senior managers differed in the intensity of their social media searching behaviours. On the one hand, social media is not formally in use for searching and generating new products ideas in some leading companies, as noted by the CIO of Company L: '... in terms of new product ideation, we only use social media as an informal source of information to support our decision making, especially to a multinational corporation like us. I believe for some other industries or SMEs, it [social media] might be more related.' For instance, Company L heavily rely on their own R\&D centres, which are dedicated to identifying and generating continuous new product ideas for innovation. The R\&D director of Company L further mentioned that 'In general, we depend on our own R\&D to generate ideas for our new products, we then qualify and verify them for further development', indicating a low level of searching intensity of using social media in product ideation. On the other hand, the vice general manager of Company A characterised searching behaviours as intense: 'We use social media intensively in order to generate actionable insights related to new product ideas and designs that can be progressed and subsequently launched.' For example, among the cases, Companies $\mathrm{A}$ and $\mathrm{H}$ built a social media team that not only monitors social media feedback from its hosted online platforms at all hours, but also works interactively with different agency partners to generate useful and authentic content. A senior R\&D team member of Case $\mathrm{H}$ commented that 'Searching for new product ideas via a social media built-in system is vital, to not only identify what is being discussed about your product, but also to gain insightful 
knowledge about competitors' marketing strategies, industry trends and new product announcements.

These findings suggest that managers have different searching modes to leverage social media for knowledge acquisition in the product ideation phase. However, they need to apply appropriate searching modes in line with the heterogeneous nature of NPD projects. The cases show that NPD projects with a high degree of social media searching activities tend to adopt a customer-focused organisational culture. According to Cooper (2016), customer focus refers to a business philosophy that positions customer value and opportunities at the centre of every company decision. Social media introduced novel customer-focused applications that enable companies to interact with customers and other stakeholders during the NPD process. Typically, it is highlighted as a critical marketing strategy. However, the findings indicate that a customer-focused culture is perceived by operations, product R\&D and data analytics as essential to their primary roles. As stated by the technical director of Case $\mathrm{H}$, 'we implemented a customer-focused culture within our department. We have strived to integrate our social media searching activities to develop a unified infrastructure permeating all networks, products and businesses'. Besides, integrating a customer-focused culture to the searching activities views the customer as the unit of analysis. It can help to identify the appropriate questions to ask and support companies to apply relevant cases, which transform sophisticated social media data into exploratory behaviours, prescriptive models, and fact-based decisions. This leads to the following proposition:

Proposition 1. The degree of social media searching intensity for product ideation is higher when the company has a higher level of diffused customer-focused culture.

Searching proactiveness concerns not just time and effort invested in knowledge acquisition by searching, but the effectiveness of using social media to acquire different or better knowledge than competitors. For example, Company $\mathrm{H}$ developed a novel system of social media scanning to present a set of new product features in different categories, and asked respondents how and why one product feature differed from others. Company I performed analyses to interpret the data and provide a summary of the underlying reasons (or a list of articulated requirements) for new product options. Through such proactive data collection and analysis, the case companies identified external forces of change and established effective responses to improve or secure their new products in the future. The vice general manager of Case A noted the following: 'The proactiveness of the use of social media can help to gain 
competitive advantages through identifying external threats and opportunities, avoiding unexpected occurrences and improving short-term and long-term planning. ' In contrast, a few case companies demonstrated passiveness in their information search tendencies. As the chief technical officer of Company L frankly commented: 'We use social media just to see how customers will react to our products, this supports us in making informative decisions for future $N P D$.' For product ideation, these companies prefer to carry out deeper research with their stakeholders through other, more traditional methods. According to the open innovation senior manager of Company I: 'I think social media is very unreliable and dangerous. The information on social media is changing extremely fast. We can't post much information there to gather the relevant insights, though we do sometimes, but again, less in practice.'

The findings indicate that information acquisition cannot be adequately conducted by analysing searching intensity only. The proactiveness of searching was another distinctive form of leveraging social media for product ideation. Notably, the cases reveal that a data-driven culture plays an essential role in improving the effectiveness of social media search proactiveness for product ideation. According to Davenport (2012), a data-driven culture possesses data as a critical resource for generating decisions and insights in every department of the company. This cultural suggests that an experimental process relying on hypothesis testing and data integration to generate new insights can enhance social media searching performance and overall performance of the project. For example, the vice general manager of Case A commented: 'people can always find an explanation for anything but without knowing whether it is right or not. I would like to cultivate a cultural shift across the company through encouraging the conviction that decisions should be made by data analysis, while depending less on experience and intuition'. More specifically, when managers considered that their companies have a data-driven culture, they will be more frequent and motivated to use social media in searching for knowledge activities. Also, these managers tend to dedicate more effort to ensure that they stayed on the cutting edge of knowledge development in their areas. Thus, we propose:

Proposition 2. The degree of social media searching proactiveness for product ideation is higher when the company has a higher level of diffused data-driven culture. 


\subsection{Collective Learning for $R \& D$}

The analysis identified an important ability of the case companies to effectively leverage social media to identify emerging trends and generate new insights, which were sent back to internal production processes. This mechanism is termed here collective learning for $\mathrm{R} \& \mathrm{D}$, and refers to the knowledge synergies that emerge from collaborative NPD on social media. This is consistent with the theory of open innovation, which states that access to a wide range of capabilities, knowledge and skills enables individuals to integrate different solutions into coherent and innovative ideas (West et al., 2014).

The first subtheme is external accessibility, representing whether company knowledge from external environments can be easily obtained. In this regard, many companies (e.g. cases B, D and $\mathrm{G}$ ) had adopted external digital agencies to deal with their social media data and knowledge integration process. For instance, a critical issue encountered by Company D was an internal constraint on harvesting values from the sheer volume of user-generated content on different social media platforms. The adoption of crowdsourcing intermediaries to manage the social space was therefore essential to ensure that emerging trends and new product insights were formalised and integrated to facilitate R\&D processes. Additionally, external accessibility was supported through community development, which is one of the approaches used to enable user co-development, and refers to the process through which companies leverage customer interests and desires by creating communities of like-minded individuals. Particularly, all the cases were found to cultivate a diverse range of officially recognised social media platforms and online communities for customers with different interests. Content on social media is in real time, with both consumers and employees of the companies interacting and contributing to product R\&D. When asked about the development of the company's social media community, the CIO of Case G stated the following: 'The key to cultivating a successful social media community is being active. We need to post updates and news frequently to give customers a sense of community, so they feel they are an important part of the NPD team.'

The findings show that external information accessibility is enhanced by significant support from senior management. This is always reflected in a powerful manager who champions the implementation of social media-enabled NPD projects and overcomes challenges that might generate in the company (Troilo et al., 2017). The manager is always at the executive level who is keen to implement the project based on the previous successful experience of social media projects, or has distinct knowledge about novel social media opportunities. In our study, most 
of the cases have invested significant resources (including financial support, internal social media infrastructure and platform choices) in social media implementation and development. Compared to the investments on the integration with external digital agencies, some cases received support from senior management with the development of new functional teams focused on establishing commitment toward social media-enabled innovation. For instance, Case E developed a "social media innovation group", which communicates to the CIO but has no direct connections with other departments. The group is responsible for cultivating social media communities, incorporating customers' knowledge to identify novel innovation opportunities, and communicating them to relevant R\&D teams. It is also responsible for disseminating the latest progress to the rest of the company by weekly reports, intending to improve internal communication of social media-enabled NPD projects. The previous head of the R\&D department noted: 'More than just socialising, it is vital to transform social media into useful information, representing customers, suppliers, analysts and partners towards social media-enabled innovation.' This leads to the following proposition:

Proposition 3. The external accessibility of social media for product R\&D is higher when the level of social media-enabled innovation is higher.

Project novelty refers to the degree of a project's importance and innovativeness, as perceived by the project managers, in terms of its influences on the success of the company. Among the cases, managers differed in their ascriptions of the knowledge domain critical to their companies. Some reported that achieving product novelty was important to success. Others also appreciated innovativeness but suggested it was more essential to achieve operational process control and product cost efficiency. For instance, the head of innovation of Company $\mathrm{B}$ highlighted the significance of project novelty: 'We are receiving an increasing number of design and engineering specifications from social media. Thus, our product engineers are developing some very novel functional features to satisfy our customers. That's the reason why it is critical that we work on the cutting-edge of technology.' This finding suggested that it was the utilisation of social media activities that led to the exploration and development of new product lines. Nevertheless, the senior IT project manager of nearby Company G argued for the importance of efficiency as an approach to controlling costs and uncertainties. The case analysis demonstrates that Companies $\mathrm{G}$ and $\mathrm{K}$ are using social media through a "panentertainment strategy' - the development of multilevel products on the basis of a company's existing intellectual property (e.g. animation, information, customers, patents, fiction and 
games). This approach allows companies to link new/improved content across a variety of platforms to engage viewers and content creators. The R\&D project leader of Company $\mathrm{K}$ emphasised the importance of the pan-entertainment strategy: 'We don't develop products that are entirely new. The values of applying a pan-entertainment strategy can lead to a reduced marginal cost, lower risk of initial investment and improved customer base growth to stimulate return on investment. The company has targeted the pan-entertainment strategy as one of their key objectives for the future social media supported NPD.'

Although highly novel projects are critical to business success, they involve a high level of uncertainty and thus need an exploration-focused approach (e.g. radical innovation). With a low level of novelty, the NPD teams act mostly with their existing knowledge acquired from years of experience in attempting to improve the efficiency of their production and operations processes (e.g. incremental innovation). The findings suggest that customer education becomes an effective way of improving the impact of both high and low novelty projects on the use of social media for product R\&D. Customer education refers to an organisation's role to provide their customers with the skills, abilities and knowledge required to use their products in a more informed way (Lee et al., 203). The interviews show that most of the case companies announced customer education-oriented messages regularly to make customers more familiar and comfortable with their new products. As in this statement from the head of IT department of Case D: 'In today's big data era, customers are becoming increasingly aware of the power of information and their role in product $R \& D$. Thus, it requires companies to be able to convey their knowledge back to consumers in a manner that they can directly recognise and obtain values from'. The findings imply that customer education shifts from as an individual level capability to a firm level capability that can strengthen the impact of social media in product $\mathrm{R} \& \mathrm{D}$, in terms of improved project novelty, cost-effectiveness and customer experience. Thus, we propose:

Proposition 4. The relationship between project novelty and the success of social media-enabled product $R \& D$ is moderated by the level of customer education implemented by the company.

\subsection{Fast-launch-and-improve Cycle for Testing and Launch}

The data analysis identified the fast-launch-and-improve cycle as another essential mechanism, which illustrates how social media was actually applied to create competitive advantage. This 
pattern is evident in the following quotation from the vice general manager of Case C: 'It is essential to acquire and integrate information, but that doesn't make you successful. Employing what you learnt is what makes you successful. The use of social media as a testand-learn toolkit is what really causes the difference. Many people don't know this, and it could be the key to the whole business.' Here, 'knowledge-in-action' is used as the label for this pattern as the case companies consistently mentioned the terms 'intelligent' and 'appropriate' application of social media in daily operations. Two distinct types of knowledge-in-action were identified in the findings: information processing and information transformation.

Information processing concerns actions that confer a capability to leverage social media to support specific operational activities and offer digital services in NPD. The focus is on developing digital solutions to address local challenges through creativity and ingenuity. In some companies, this pattern of knowledge-in-action was regarded as the capability to 'tweak' social media. For example, Companies C, F and J established product improvement units within their IT departments to process valuable inputs from different sources and convey the information to relevant NPD teams quickly. The unit serves the role of business analyst, with one of its fundamental objectives being to process useful knowledge from social media and provide valuable feedback as inputs to facilitate the process of product modification and launch. This reactive improvement approach allows R\&D teams to relaunch the product quickly and trigger further innovation. In addition, comparison of the interviews revealed a distinct approach showing that these companies follow a capabilities-driven strategy. That is, rather than developing a 'fully-fledged' product before launch, they centralise the new product's core capabilities and routinely launch new products quickly, and then pay close attention to process the feedback that they receive from partners and customers. This pattern is exemplified by the following comment from the VP technology of Case F: 'It [social media for information processing] has proven to be especially effective in market segments that are fluid and fast growing, that are populated with many open-minded consumers and first-time buyers. It allows companies to spend less time and money that would typically be required to launch new products and identify its customers' requirements.'

The findings provide evidence that by establishing a centralised analytics team within the IT department can improve the information processing of social media and facilitate problemsolving. The interviews suggest that most case companies take this initial action when they choose to achieve a social media transformation. It enables companies and NPD managers to 
verify the feasibility and opportunity of social media, by learning how analytical thinking and skills influence the effectiveness and efficiency of daily operations. Through centralising analytical thinking and skills within the IT department, companies can also get the opportunity to check their adaptability to the data-driven culture. Particularly, the findings show that centralised analytics team can improve the effectiveness of social media-enabled NPD processes, which is in line with Troilo et al. (2017), who argue that the development of a centralised analytics team within the IT department can improve data management capability and create actual innovations in NPD. Besides, the centralised analytics team is informally participate the educational part of unlocking the power of analytics, and verifying their underlying rationale in NPD activities. As a result, with an empowered centralised analytics team, the IT department can take a managerial role in determining social media-enabled NPD projects, and handing over the projects to relevant R\&D teams for facilitating the NPD process. Thus, we propose:

Proposition 5. The information processing of social media for product testing and launch is stronger when there is a higher level of centralised analytics team within the IT department.

Information transformation represents those activities that involve problem solving with an orientation towards critiquing, questioning and reflecting, in a fashion that explores new insights and understandings of an issue. The main focus here is less on addressing a specific issue and more on applying the company's social media skills and expertise to go beyond a given issue to foster new insights for further developments. For instance, the VP of technology of Company M stated the following about understanding the keys to using social media for competitive advantage: 'We test throughout the product life cycle rather than at the very end. By connecting with customers on social media, it empowers customers and opens the discussion up to the user crowd, thereby overcoming company barriers and transferring information to new product insights.' A critical aspect of information transformation was the development of a social context wherein company stakeholders were actively motivated to discuss existing knowledge of things, generate new insights and become involved in attempts to enhance collective learning on a specific production issue. Particularly, Companies C, F, J and $\mathrm{M}$ viewed this mode of knowledge-in-action as referring to the capability to leverage social media as an ideal medium, as reported in the following quotation from the head of R\&D department for Case J: 'We applied our internal intranet and social media to connect our 
knowledge employees worldwide, enabling them to share the latest information, discuss, generate and explore enriched understandings to develop principles for future developments that can improve the company's competitiveness.'

It was suggested that the establishment of a centralised analytics team within the IT department can improve the information processing of social media. Nonetheless, the findings illustrate that placing data analysts in every department that needs them, companies can improve the information transformation of social media that drive new insights. The rationale here is to disseminate a data-driven culture, and to provide every department with analytical thinking and skills that can be used to enhance data-driven decision making. For example, when discussing innovation, the R\&D senior manager of Case M commented: 'data analysts are as a virus that needs spread to the whole organisation.' The interviews validate the significance of this approach among the case companies. It provides different examples regarding how data analysts in different departments tested prescriptive analytical models irrelevant to specific company requirements, but instead generated from a probe-and-learn process. This process is related to a greater level of re-evaluation to create novel, enhanced insights into understanding issues in principle. It offers the company with great opportunities such as the development of next-generation products based on cutting-edge technologies from new experience and learnings during the NPD. Also, it supplies innovation approaches with new ideas that differ from the formalised NPD process of the company. In this way, the knowledge was transferred from the project level to the company level. This result aligns with Koskinen and Vanharanta (2002), Cooper (2016) and Hullova et al. (2019), who identified that companies can depend on the learnings from a specific project in the advancement of future innovations. This leads to the following proposition:

Proposition 6. The information transformation of social media for product testing and launch is stronger when analytical thinking and skills are highly decentralized across various departments.

\section{Conclusion}

Many researchers have pointed out social media could play various roles for company to engage consumers and to improve NPD (Sethi et al., 2003; Decker et al., 2005; Huang et al., 
2017). However, the mechanisms through which social media can be leveraged for organisational learning, facilitating innovation and generating new ideas throughout the entire NPD process remain underexplored in the literature. Most prior literature has focused on social media applications in the product ideation and design phases, and ignored social media's critical approaches during product R\&D and testing and launch (Kim and Wilemon, 2002; Sigala, 2012; Zhu et al., 2017). By assimilating the themes and categories presented in Figure 1 , this research synthesises the six propositions and summarises the major concepts and their connections in a general form (see Figure 2) that works as a blueprint for NPD project managers to effectively leverage social media for organisational learning as well as facilitating innovation throughout the entire NPD process. In essence, the framework identifies three interdependent essential mechanisms and relevant organisational enablers that facilitate the connections between these mechanisms and NPD performance. Although these mechanisms are not in themselves distinct from the innovation management literature, what is novel is how the mechanisms are linked and reinforce one another. This analysis demonstrated that the three mechanisms of leveraging resources through social media constitute an open innovation ecosystem. The iteration of company and network resources throughout this ecosystem can help to obtain critical components and requirements of the NPD process in launching new products effectively in relation to speed, cost and quality. This suggests that companies should focus on the interaction between the mechanisms rather than implementing them individually. It is vital to develop a more systematic approach to leveraging social media in NPD throughout the innovation phases. 


\section{Figure 2: Research framework for leveraging social media in NPD}

From an organisational learning point of view, the use of social media has a positive impact on effectiveness and innovativeness across all phases. In terms of product ideation, by enabling stakeholders to contribute and collaborate, companies could seek dual processes of innovation exploitation and exploration. Particularly, stakeholders were able to provide incremental improvements as well as radical new ideas to support ideation without too many internal constraints. In this way, social media offered an environment for organisational ambidexterity during the process. During product $R \& D$, the tendency for ambidexterity decreased as the main resources and development activities were allocated towards either radical or incremental innovation. As products moved from the mid-phase to formal launch and testing, the findings suggest that the application of social media had a positive influence on incremental innovation and the exploitation learning process.

\subsection{Implications for Research and Practice}

This research contributes to innovation and knowledge management literature by identifying three mechanisms by which companies can leverage social media to facilitate NPD. Particularly, the research findings complement existing literature on using social media for knowledge acquisition, proposing that it is not just how intensely managers' notice and search, but how they manage to obtain better information than their competitors (He et al., 2017; Cheng et al., 2018). In addition, this study identifies collective learning for R\&D as a mechanism for using social media to facilitate NPD. It appears to be one of the key factors of dynamic capabilities determined by Nag et al. (2007), which implies company's capability to implement internal learning and combine it with external sources of knowledge. Also, it complements prior literature on identity shifts to encourage companies to transfer from product-centric and to user-centric innovation in NPD (Hoyer et al., 2010; Cooper, 2016; Neeley and Leonardi, 2018). For the identified mechanism of fast-launch-and-improve cycle, the idea of knowledgein-action and its two inherent patterns can be used to fill in the gaps not only from the microlevel of study regarding different kinds of innovations, such as radical vs. incremental (Ritala and Hurmelinna-Laukkanen, 2013), but also from an macro or organisational level, to support the notion of double- and single-loop learning (Argyris, 1976). While prior research notes that social media offers negligible marginal costs, providing great potential for NPD (Mangold and Faulds, 2009; Mount and Martinez, 2014), this research extends the idea of this advantage by providing further case evidence of a critical mechanism of fast-launch-and-improve cycle. 
This research has several practical implications for companies in emerging markets in general, and China in particular. Given the size and rapid growth rate of China's economy, the Chinese social media market has emerged as an important context for studying NPD. Accordingly, the research is intended as a blueprint for business — whether multinational or local — to implement social media resources efficiently and effectively. A practical insight for managers, thus, is that given the complexity of daily NPD activities, the findings offer managers in high-tech companies with various insights on how to extract the enormous potential values of social media to enhance NPD. Such values can be achieved by different mechanisms, supported by specific organisational enablers. Besides, the findings suggest that there is no alleged best practices, as these differ among companies and rely on the fundamental beliefs and activities of project leaders. Although the introduction of the mechanisms identified in this study may impose considerable stress, any difficulties incurred will be more than compensated by the growth of the customer base and improvements in the effectiveness, innovativeness and market performance of the NPD process.

\subsection{Limitations and Future Research}

This research has some limitations. In particular, both the core strength and weakness of this research rests on the fact that all case companies selected were Chinese. While this enabled the choosing of the most representative cases to provide an in-depth understanding of how social media is used and implemented for NPD and organisational learning across all phases of the innovation funnel, it also limited generalisability. However, this approach was followed in light of the fact that no rich empirical evidence exists in the innovation and knowledge management literature, despite its importance for theory and practice. Moreover, while the focus on a single country/industry could be regarded as a limitation, it also enables a richer and deeper understanding of the elements of competitive heterogeneity with various contextual conditions remaining more or less consistent, which would be challenging in a multi-country/industry investigation. Further, the cases collectively provide coverage of different high-tech companies. Although diversity exists in the high-tech industry, the key mechanisms of leveraging social media in NPD are shared among all industries, given that social media is a relatively 'low-content' technology and can be generalised across different contexts (Adner and Kapoor, 2010; Chiu et al., 2012). Thus, the research findings can be somewhat extended, and advance policy and practice beyond the high-tech industry and Chinese context. Future empirical research could be developed in different countries and industries with different levels 
of technology to reinforce the propositions put forward here. Despite the limitations, this research on leveraging social media in NPD sheds light on innovation and knowledge management research. This is still an emerging topic in operations and production management, and it is hoped that the identified mechanisms will offer a new way to integrate the diversity of research on digital product development and social media to stimulate both practice and research.

\section{References}

Adner, R. and R. Kapoor. (2010), "Value creation in innovation ecosystems: how the structure of technological interdependence affects firm performance in new technology generations", Strategic Management Journal, Vol. 31 No. 3, pp. 306-333.

Aral, S. and Walker, D. (2011), "Creating social contagion through viral product design: a randomised trial of peer influence in networks", Management Science, Vol. 57 No. 9, pp. 1623-1639.

Argyris, C., 1976. Single-loop and double-loop models in research on decision making. Administrative science quarterly, pp.363-375.

Atuahene-Gima, K. and Murray, J.Y., 2007. Exploratory and exploitative learning in new product development: A social capital perspective on new technology ventures in China. Journal of International Marketing, 15(2), pp.1-29.

Barnes, N.G. and Pavao, S. (2017), The 2017 Furtune 500 Go Visual and Increase Use of Instagram, Snapchat, and YouTube, available at: https://www.umassd.edu/cmr/socialmediaresearch/2017fortune500/ (accessed 16 September 2018).

Bharati, P., Zhang, W. and Chaudhury, A., 2015. Better knowledge with social media? Exploring the roles of social capital and organisational knowledge management. Journal of Knowledge Management, 19(3), pp.456-475.

Brexendorf, T.O., Bayus, B. and Keller, K.L. (2015), "Understanding the interplay between brand and innovation management: findings and future research directions", Journal of the Academy of Marketing Science, Vol. 43, pp. 548- 557.

Cheng, T.C.E., Lam, H.K., Lyons, A.C. and Yeung, A.C. (2018), "The use of social media in operations and supply chain management", International Journal of Operations \& Production Management, available at:

http://www.emeraldgrouppublishing.com/products/journals/call_for_papers.htm?id=7949 (accessed 02 September 2018).

Chiu, C., Ip, C. and Silverman, A. (2012), “Understanding social media in China”, McKinsey Quarterly, Vol. 2, pp.78-81.

Clarivate Analytics (2017), 2017 Top 100 Chinese Innovators, available at https://www.clarivate.com.cn/Innovation2017/2017 Top 100_Chinese_Innovators_EN_FIN AL.pdf (accessed 22 February 2018). 
Cook, S.D. and Brown, J.S., 1999. Bridging epistemologies: The generative dance between organisational knowledge and organisational knowing. Organisation science, 10(4), pp.381400.

Cooper, R.G. (2016), “Agile-stage-gate hybrids: the next stage for product development blending agile and stage-gate methods can provide flexibility, speed, and improved communication in newproduct development”, Research-Technology Management, Vol. 59 No. 1, pp. 21-29.

Culnan, M.J., McHugh, P.J. and Zubillaga, J.I. (2010), "How large US companies can use Twitter and other social media to gain business value", MIS Quarterly Executive, Vol. 9 No. 4, pp. 243 259.

Daft, R.L., Sormunen, J. and Parks, D., 1988. Chief executive scanning, environmental characteristics, and company performance: An empirical study. Strategic management journal, 9(2), pp.123139.

Decker, R., Wagner, R. and Scholz, S.W. (2005), "An internet-based approach to environmental scanning in marketing planning", Marketing Intelligence \& Planning, Vol. 23 No. 2, pp. 189199.

Du, S., Yalcinkaya, G. and Bstieler, L. (2016), "Sustainability, social media driven open innovation, and new product development performance", Journal of Product Innovation Management, Vol. 33 , pp. 55-71.

Eisenhardt, K.M. (1989), "Building theories form case study research", Academy of Management Review, Vol. 14, pp. 532-550.

Felix, R., Rauschnabel, P.A. and Hinsch, C. (2017), "Elements of strategic social media marketing: a holistic framework", Journal of Business Research, Vol. 70, pp. 118-126.

Franke, N. and Piller, F. (2004), "Value creation by toolkits for user innovation and design: the case of the watch market", Journal of Product Innovation Management, Vol. 21 No. 6, pp. 401-415.

Hagel, J. and Brown, J.S. (2011), "Creation nets: harnessing the potential of open innovation", Journal of Service Science, Vol. 1 No. 2, pp. 27-40.

Hanna, R., Rohm, A. and Crittenden, V.L. (2011), "We're all connected: the power of the social media ecosystem”, Business Horizons, Vol. 54 No. 3, pp. 265-273.

He, W., Wang, F.K. and Akula, V. (2017), "Managing extracted knowledge from big social media data for business decision making", Journal of Knowledge Management, Vol. 21 No. 2, pp. 275294.

Hemsley, J. and Mason, R.M., 2013. Knowledge and knowledge management in the social media age. Journal of Organizational Computing and Electronic Commerce, 23(1-2), pp.138-167.

Hoyer, W.D., Chandy, R., Dorotic, M., Krafft, M. and Singh, S.S. (2010), "Consumer cocreation in new product development”, Journal of Service Research, Vol. 13 No. 3, pp. 283-296.

Huang, J., Henfridsson, O., Liu, M.J. and Newell, S. (2017), "Growing on steroids: rapidly scaling the user based of digital ventures through digital innovation", MIS Quarterly, Vol. 41 No. 1, pp. 301-314.

Hullova, D., Simms, C.D., Trott, P. and Laczko, P., 2019. Critical capabilities for effective management of complementarity between product and process innovation: Cases from the food and drink industry. Research Policy, 48(1), pp.339-354.

Internet World Stats: Usage and Population Statistics (2018), Internet World Stats, available at: https://www.internetworldstats.com/america.htm (accessed 10 January 2019). 
Kane, G.C. and Alavi, M., 2007. Information technology and organisational learning: An investigation of exploration and exploitation processes. Organization Science, 18(5), pp.796-812.

Kim, J. and Wilemon, D. (2002), "Focusing the fuzzy front-end in new product development", $R \& D$ Management, Vol. 32 No. 4, pp. 269-279.

Koskinen, K.U. and Vanharanta, H., 2002. The role of tacit knowledge in innovation processes of small technology companies. International journal of production economics, 80(1), pp.57-64.

Lam, H.K., Yeung, A.C. and Cheng, T.E. (2016), "The impact of firms' social media initiatives on operational efficiency and innovativeness", Journal of Operations Management, Vol. 47, pp. $28-43$.

Lee, Y. and Colarelli O'Connor, G., 2003. The impact of communication strategy on launching new products: The moderating role of product innovativeness. Journal of Product Innovation Management, 20(1), pp.4-21.

Leonardi, P.M., 2015. Ambient awareness and knowledge acquisition: using social media to learn 'who knows what'and 'who knows whom'. MIS Quarterly, 39(4), pp.747-762.

Lüthje, C. and Herstatt, C. (2004), "The lead user method: an outline of empirical findings and issues for future research", $R \& D$ Management, Vol. 34 No. 5, pp. 553-568.

Mangold, W.G. and Faulds, D.J. (2009), "Social media: the new hybrid element of the promotion mix", Business Horizons, Vol. 52 No. 4, pp. 357-365.

Manyika, J., Chui, M., Farrell, D., Van Kuiken, S., Groves, P. and Almasi Doshi, E. (2013), Open Data: Unlocking Innovation and Performance with Liquid Information, McKinsey Global Institute.

Meredith, J. (1998), "Building operations management theory through case and field research", Journal of Operations Management, Vol. 16 No. 4, pp. 441-454.

Miles, M.B. and Huberman, A.M. (1984), Qualitative Data Analysis: A Sourcebook of New Methods, Sage.

Miller, C.C., Cardinal, L.B. and Glick, W.H., 1997. Retrospective reports in organisational research: A reexamination of recent evidence. Academy of Management Journal, 40(1), pp.189-204.

Mount, M. and Martinez, M.G. (2014), "Social media: a tool for open innovation", California Management Review, Vol. 56 No. 4, pp. 124-143.

Nag, R. and Gioia, D.A. (2012), "From common to uncommon knowledge: foundations of firm-specific use of knowledge as a resource", Academy of Management Journal, Vol. 55 No. 2, pp. 421457.

Nag, R., Corley, K.G. and Gioia, D.A., 2007. The intersection of organisational identity, knowledge, and practice: Attempting strategic change via knowledge grafting. Academy of Management Journal, 50(4), pp.821-847.

Nambisan, S. (2002), "Designing virtual customer environments for new product development: toward a theory", Academy of Management Review, Vol. 27 No. 3, pp. 392-413.

Nambisan, S. and Baron, R.A. (2010), "Different roles, different strokes: organising virtual customer environments to promote two types of customer contributions", Organization Science, Vol. 21 No. 2, pp. 554-572.

Neeley, T.B. and Leonardi, P.M. (2018), "Enacting knowledge strategy through social media: passable trust and the paradox of nonwork interactions", Strategic Management Journal, Vol. 39 No. 3, pp. 922-946. 
Nguyen, B., Yu, X., Melewar, T.C. and Chen, J., 2015. Brand innovation and social media: Knowledge acquisition from social media, market orientation, and the moderating role of social media strategic capability. Industrial Marketing Management, 51, pp.11-25.

Pentland, B.T., 1992. Organising moves in software support hot lines. Administrative Science Quarterly, pp.527-548.

Piller, F.T., Vossen, A. and Ihl, C. (2011), "From social media to social product development: the impact of social media on co-creation of innovation”, SSRN Scholarly Paper No. 1975523, Social Science Research Network, Rochester, NY, available at: http://papers.ssrn.com/abstract=1975523 (accessed 08 July 2018).

Ramanathan, U., Subramanian, N. and Parrott, G. (2017), "Role of social media in retail network operations and marketing to enhance customer satisfaction", International Journal of Operations \& Production Management, Vol. 37 No. 1, pp. 105-123.

Ritala, P. and Hurmelinna-Laukkanen, P., 2013. Incremental and radical innovation in coopetitionThe role of absorptive capacity and appropriability. Journal of Product Innovation Management, 30(1), pp.154-169.

Robert Jr, L.P., Dennis, A.R. and Ahuja, M.K., 2008. Social capital and knowledge integration in digitally enabled teams. Information systems research, 19(3), pp.314-334.

Roberts, D.L. and Candi, M. (2014), "Leveraging social network sites in new product development: opportunity or hype?", Journal of Product Innovation Management, Vol. 31, pp. 105-117.

Roberts, D.L., Piller, F.T. and Lüttgens, D. (2016), "Mapping the impact of social media for innovation: the role of social media in explaining innovation performance in the PDMA Comparative Performance Assessment Study", Journal of Product Innovation Management, Vol. 33, pp. 117-135.

Rojo, A., Stevenson, M., Lloréns Montes, F.J. and Perez-Arostegui, M.N., 2018. Supply chain flexibility in dynamic environments: The enabling role of operational absorptive capacity and organisational learning. International Journal of Operations \& Production Management, 38(3), pp.636-666.

Sethi, R., Pant, S. and Sethi, A. (2003), "Web-based product development systems integration and new product outcomes: a conceptual framework", Journal of Product Innovation Management, Vol. 20 No. 1, pp. 37-56.

Sigala, M. (2012), "Social networks and customer involvement in new service development (NSD): the case of www.mystarbucksidea.com", International Journal of Contemporary Hospitality Management, Vol. 24 No. 7, pp. 966-990.

Stevens, E. and Dimitriadis, S., 2004. New service development through the lens of organisational learning: evidence from longitudinal case studies. Journal of Business Research, 57(10), pp.1074-1084.

Strauss, A. and Corbin, J. (1990), Basics of Qualitative Research, Sage.

Strauss, A. and Corbin, J. (1994), "Grounded theory methodology", Handbook of Qualitative Research, Vol. 17, pp. 273-285.

Tan, K.H. and Zhan, Y. (2017), "Improving new product development using big data: a case study of an electronics company", $R \& D$ Management, Vol. 47 No. 4, pp. 570-582.

Tidd, J. and Bessant, J.R., 2018. Managing innovation: integrating technological, market and organisational change. John Wiley \& Sons. 
Tóth, Z., Liu, M., Luo, J. and Braziotis, C., 2019. The role of social media in managing supplier attractiveness. International Journal of Operations \& Production Management. https://doi.org/10.1108/IJOPM-04-2019-0321

West, J., Salter, A., Vanhaverbeke, W. and Chesbrough, H. (2014), “Open innovation: the next decade”, Research Policy, Vol. 43 No. 5, pp. 805-811.

Williamson, P.J. and Yin, E. (2014), "Accelerated innovation: the new challenge from China", MIT Sloan Management Review, Vol. 55 No. 4, pp. 27-34.

Woetzel, J., Chen, Y., Manyika, J., Roth, E., Seong, J. and Lee, J. (2015), The China Effect on Global Innovation, McKinsey Global Institute.

Yin, R.K. (2011), Applications of Case Study Research. Sage.

Zhan, Y., Tan, K.H., Li, Y. and Tse, Y.K. (2016), "Unlocking the power of big data in new product development”, Annals of Operations Research, Vol. 270, No. 1-2, pp. 577-595.

Zhu, J.J., Li, S.Y. and Andrews, M. (2017), "Ideator expertise and cocreator inputs in crowdsourcing-based new product development", Journal of Product Innovation Management, Vol. 34 No. 5, pp. 598-616. 


\begin{tabular}{|c|c|c|c|c|c|}
\hline \multirow[b]{2}{*}{ Cases } & \multirow{2}{*}{ Aim of the project } & \multirow[b]{2}{*}{ Implementation } & \multirow[b]{2}{*}{ Impacts } & \multicolumn{2}{|c|}{ Knowledge Acquisition } \\
\hline & & & & Searching intensity & Searching proactiveness \\
\hline A & $\begin{array}{l}\text { Use social media in } \\
\text { ideation and design } \\
\text { for a new service } \\
\text { package. }\end{array}$ & $\begin{array}{l}\text { Adopt integrated applications and } \\
\text { interconnected } \\
\text { communities/networks to layer } \\
\text { various social media channels. }\end{array}$ & $\begin{array}{l}\text { Reported } 56 \% \text { growth in } \\
\text { number of the } \\
\text { participants across its } \\
\text { social media ideation } \\
\text { networks. }\end{array}$ & $\begin{array}{l}\text { Always 'keep eyes open' } \\
\text { and use social media to } \\
\text { monitor certain market } \\
\text { performance closely. }\end{array}$ & $\begin{array}{l}\text { Very active in using } \\
\text { social media to identify } \\
\text { and search for unusual } \\
\text { information. }\end{array}$ \\
\hline $\mathrm{H}$ & $\begin{array}{l}\text { Engage young } \\
\text { activists in idea } \\
\text { generation for social } \\
\text { innovation. }\end{array}$ & $\begin{array}{l}\text { Identify and apply external source to } \\
\text { support such as social media service } \\
\text { providers, digital agencies and data } \\
\text { intermediaries. }\end{array}$ & $\begin{array}{l}\text { Social media offered an } \\
\text { environment for } \\
\text { organisational } \\
\text { ambidexterity during the } \\
\text { ideation process. }\end{array}$ & $\begin{array}{l}\text { Pay attention to the use of } \\
\text { social media and spend } \\
\text { much effort to monitor } \\
\text { various social media } \\
\text { platforms all the time. }\end{array}$ & $\begin{array}{l}\text { Listen, discuss and } \\
\text { observe daily activities } \\
\text { and try to think about how } \\
\text { to improve the current } \\
\text { situation. }\end{array}$ \\
\hline $\mathrm{I}$ & $\begin{array}{l}\text { Use social media to } \\
\text { generate novel new } \\
\text { product ideas that } \\
\text { could be further } \\
\text { developed. }\end{array}$ & $\begin{array}{l}\text { Integrating social media content } \\
\text { with existing database and systems. }\end{array}$ & $\begin{array}{l}\text { Higher quality in terms } \\
\text { of ideas generated. }\end{array}$ & $\begin{array}{l}\text { Keep searching for new } \\
\text { information; interact with } \\
\text { lead innovators regularly. }\end{array}$ & $\begin{array}{l}\text { Gaining and evaluating } \\
\text { the subtle things that are } \\
\text { prevalent on social media. }\end{array}$ \\
\hline $\mathrm{L}$ & $\begin{array}{l}\text { New campaign to } \\
\text { identify new product } \\
\text { features and improve } \\
\text { brand awareness. }\end{array}$ & $\begin{array}{l}\text { Use social media as an informal } \\
\text { source of information to provide a } \\
\text { summary for new product options. }\end{array}$ & $\begin{array}{l}\text { Facilitated time-to- } \\
\text { market and reduced cost } \\
\text { for ideation activities } \\
\text { were documented. }\end{array}$ & $\begin{array}{l}\text { Created a special } \\
\text { production procedure to } \\
\text { connect research with } \\
\text { market information. }\end{array}$ & $\begin{array}{l}\text { Offer freedom and } \\
\text { resources to encourage } \\
\text { innovators; apply social } \\
\text { media to understand the } \\
\text { market. }\end{array}$ \\
\hline
\end{tabular}




\section{Appendix B: Summary of cross-case findings: Collective learning for product R\&D}

\begin{tabular}{|c|c|c|c|c|c|}
\hline \multirow[b]{2}{*}{ Cases } & \multirow{2}{*}{ Aim of the project } & \multirow[b]{2}{*}{ Implementation } & \multirow[b]{2}{*}{ Impacts } & \multicolumn{2}{|c|}{ Knowledge Integration } \\
\hline & & & & External accessibility & Project novelty \\
\hline B & $\begin{array}{l}\text { Engage consumers via } \\
\text { social media for } \\
\text { developing a new } \\
\text { smartphone device. }\end{array}$ & $\begin{array}{l}\text { Adopt built-in technical } \\
\text { application system on social } \\
\text { media to support open } \\
\text { innovation. }\end{array}$ & $\begin{array}{l}\text { Reported a facilitated } \\
\text { R\&D process for } \\
\text { exploration and radical } \\
\text { innovation. }\end{array}$ & $\begin{array}{l}\text { Use various sources of } \\
\text { information such as new } \\
\text { channels for R\&D } \\
\text { activities and open } \\
\text { innovation. }\end{array}$ & $\begin{array}{l}\text { Invest in high uncertainty } \\
\text { projects; have a mid- to long- } \\
\text { term perspective; focus on } \\
\text { gaining competitiveness within } \\
\text { current markets. }\end{array}$ \\
\hline $\mathrm{D}$ & $\begin{array}{l}\text { Apply social media as } \\
\text { an impact toolkit for } \\
\text { brand rejuvenation and } \\
\text { product innovation. }\end{array}$ & $\begin{array}{l}\text { Apply external agencies to } \\
\text { integrate the large amount of } \\
\text { social media data and } \\
\text { generate usable knowledge. }\end{array}$ & $\begin{array}{l}\text { Captured a diverse } \\
\text { range of customer } \\
\text { knowledge from } \\
\text { different sources } \\
\text { effectively. }\end{array}$ & $\begin{array}{l}\text { Engage external experts } \\
\text { and partners in R\&D; } \\
\text { search for new information } \\
\text { to enhance knowledge } \\
\text { base. }\end{array}$ & $\begin{array}{l}\text { Emphasis on producing a critical } \\
\text { change that transforms current } \\
\text { product markets. }\end{array}$ \\
\hline $\mathrm{E}$ & $\begin{array}{l}\text { Engage consumers in } \\
\text { research activity for } \\
\text { developing new radical } \\
\text { features. }\end{array}$ & $\begin{array}{l}\text { Develop company } \\
\text { infrastructure to enable and } \\
\text { support the development of } \\
\text { social media initiatives. }\end{array}$ & $\begin{array}{l}\text { Re-evaluate customer } \\
\text { needs and upgrade the } \\
\text { scope of its content } \\
\text { that users can enjoy. }\end{array}$ & $\begin{array}{l}\text { Rely on internal R\&D } \\
\text { capabilities; try to attract } \\
\text { the best talent to the } \\
\text { company. }\end{array}$ & $\begin{array}{l}\text { Emphasis on new products and } \\
\text { technologies with unique } \\
\text { functional features. }\end{array}$ \\
\hline G & $\begin{array}{l}\text { Use social media to } \\
\text { facilitate customer } \\
\text { engagement in product } \\
\text { R\&D. }\end{array}$ & $\begin{array}{l}\text { Adapt external intermediaries } \\
\text { to overcome the time burdens } \\
\text { of analysing and processing. }\end{array}$ & $\begin{array}{l}\text { Reported reduction of } \\
\text { project risk and } \\
\text { uncertainty. }\end{array}$ & $\begin{array}{l}\text { Explore different sources } \\
\text { for innovative production; } \\
\text { combine external } \\
\text { information to support own } \\
\text { R\&D activities. }\end{array}$ & $\begin{array}{l}\text { Prefer low to medium } \\
\text { uncertainty projects; focused on } \\
\text { enhancing current production } \\
\text { efficiency. }\end{array}$ \\
\hline $\mathrm{K}$ & $\begin{array}{l}\text { Implement social } \\
\text { media to improve an } \\
\text { existing electronic } \\
\text { tablet product features. }\end{array}$ & $\begin{array}{l}\text { Use social media technical } \\
\text { analytics to determine and } \\
\text { improve insights generated in } \\
\text { R\&D activities. }\end{array}$ & $\begin{array}{l}\text { Documented a } \\
\text { reduction of more than } \\
50 \% \text { R\&D research } \\
\text { cost. }\end{array}$ & $\begin{array}{l}\text { Exploit existing research } \\
\text { capabilities; don't find } \\
\text { value or input from } \\
\text { external sources. }\end{array}$ & $\begin{array}{l}\text { Put particular emphasis on } \\
\text { feature improvements and cost } \\
\text { reduction of existing processes } \\
\text { and products. }\end{array}$ \\
\hline
\end{tabular}




\section{Appendix C: Summary of cross-case findings: Fast-launch-and-improve for product testing and launch}

\begin{tabular}{|c|c|c|c|c|c|}
\hline \multirow[b]{2}{*}{ Cases } & \multirow[b]{2}{*}{ Aim of the project } & \multirow[b]{2}{*}{ Implementation } & \multirow[b]{2}{*}{ Impacts } & \multicolumn{2}{|c|}{ Knowledge-in-action } \\
\hline & & & & Information processing & $\begin{array}{c}\text { Information } \\
\text { transformation }\end{array}$ \\
\hline $\mathrm{C}$ & $\begin{array}{l}\text { Apply social media to } \\
\text { support product } \\
\text { testing and launch for } \\
\text { developing a new } \\
\text { application. }\end{array}$ & $\begin{array}{l}\text { Adopt add-in functions to } \\
\text { engage with various cross- } \\
\text { section of customer in } \\
\text { exploitation initiatives. }\end{array}$ & $\begin{array}{l}\text { Reported } 60 \% \text { growth in } \\
\text { product involvement on } \\
\text { social media; the total cost } \\
\text { of production was reduced } \\
\text { by } 30 \% \text { through using social } \\
\text { media. }\end{array}$ & $\begin{array}{l}\text { Always think about clever } \\
\text { ways to solve a social } \\
\text { media task; try to make it } \\
\text { effective and less costly to } \\
\text { maximise the benefits. }\end{array}$ & $\begin{array}{l}\text { Utilise networks and develop } \\
\text { absorptive capacity to } \\
\text { generate insightful views in } \\
\text { product testing and launch. }\end{array}$ \\
\hline $\mathrm{F}$ & $\begin{array}{l}\text { Adopt social media to } \\
\text { enhance market } \\
\text { performance and } \\
\text { facilitate new } \\
\text { innovations. }\end{array}$ & $\begin{array}{l}\text { Use social media } \\
\text { technological features to } \\
\text { achieve 'viral' effects of } \\
\text { new products. }\end{array}$ & $\begin{array}{l}\text { Improved product market } \\
\text { performance by } 8 \% \text { in target } \\
\text { segment; increased potential } \\
\text { product advocates. }\end{array}$ & $\begin{array}{l}\text { If an employee comes up } \\
\text { with a better way of } \\
\text { solving a task, implement } \\
\text { that new method in other } \\
\text { NPD projects. }\end{array}$ & $\begin{array}{l}\text { Harvest external good ideas, } \\
\text { discuss and share these } \\
\text { across NPD teams to } \\
\text { facilitate problem solving. }\end{array}$ \\
\hline $\mathrm{J}$ & $\begin{array}{l}\text { Use social media to } \\
\text { support and accelerate } \\
\text { the launch of new } \\
\text { products. }\end{array}$ & $\begin{array}{l}\text { Establish an internal social } \\
\text { media platform to connect } \\
\text { employees to communicate, } \\
\text { coordinate and collaborate. }\end{array}$ & $\begin{array}{l}\text { Documented facilitated } \\
\text { exploitation and incremental } \\
\text { development during product } \\
\text { testing and launch through } \\
\text { using social media. }\end{array}$ & $\begin{array}{l}\text { Keep asking questions } \\
\text { about how to do it } \\
\text { effectively, how to use } \\
\text { social media in a better } \\
\text { way, and what you can get } \\
\text { away with. }\end{array}$ & $\begin{array}{l}\text { Implement a reflective } \\
\text { learning process and apply } \\
\text { the outcomes to a bigger } \\
\text { picture to work with a } \\
\text { particular situation. }\end{array}$ \\
\hline M & $\begin{array}{l}\text { Implement social } \\
\text { media to identify the } \\
\text { main and conduct } \\
\text { various tests faster. }\end{array}$ & $\begin{array}{l}\text { Analyse social media to } \\
\text { identify customers' } \\
\text { preferences, and enable the } \\
\text { company to develop the } \\
\text { right products. }\end{array}$ & $\begin{array}{l}\text { Reported higher return on } \\
\text { investment compared with } \\
\text { traditional approaches. }\end{array}$ & $\begin{array}{l}\text { Focus on using social } \\
\text { media to solve problems } \\
\text { through small steps rather } \\
\text { than giant leaps. }\end{array}$ & $\begin{array}{l}\text { Have an open innovation } \\
\text { belief of 'innovation happens } \\
\text { elsewhere' and add the } \\
\text { science to enhance current } \\
\text { understandings. }\end{array}$ \\
\hline
\end{tabular}


27 May 2020

\section{International Journal of Operations \& Production Management}

SI: The Use of Social Media in Operations and Supply Chain Management

\section{Manuscript ID IJOPM-04-2019-0318.R2 - Comments to Editors and Reviewers}

\section{Dear Guest Editors,}

We were pleased to have an opportunity to revise our manuscript IJOPM-04-2019-0318.R2, titled "Leveraging Social Media in New Product Development: Organisaitonal Learning Processes, Mechanisms, and Evidence from China." This paper fills a gap in the literature by investigating the mechanisms on how social media can provide important platforms for organisational learning to facilitate innovation and generate new ideas throughout the entire new product development (NPD) process.

In revising the paper, we have carefully considered your comments and suggestions. Please find enclosed the revised version of the manuscript IJOPM-04-2019-0318.R2. We have made extensive modifications to the paper and the main changes are:

- Improving the findings section by making the paragraphs more consistent, and framing the propositions to make it more specific and testable.

- Revising literature section (i.e., Table 1 and Section 2.1) to make the roles of social media in NPD clearer.

- Improving the Abstract to show the research findings in a straightforward manner.

- Improving the methodology section by highlighting the time when the research was conducted.

After providing a brief overview of the ways in which the paper was revised, we then respond to each comment and suggestion in a point-by-point fashion and outline the modifications that have been made. We are very grateful for the opportunity to revise what we consider to be a worthwhile contribution to the emerging literature in this area, and welcome further feedback on route to making the paper suitable for publication in the International Journal of Operations \& Production Management.

Yours sincerely,

The Authors 


\section{SUBMISSION IJOPM-04-2019-0318.R2 MODIFICATIONS}

The paper has undergone substantial revision and rewriting to incorporate the comments and suggestions of the editors. The comments were very helpful overall, and we appreciate the very insightful and constructive feedback in response to our original submission.

\section{Comments from the Guest Editors:}

It's great to see the authors had put significant efforts to revise the paper and to address the concerns raised in the previous round of review. Overall, now the paper is easier to follow and more understandable. Still, there are a few concerns as listed below, but they should be addressable. I am looking forward to reading the revised paper.

Editors\#GENERAL OVERVIEW. We are glad to know that the editors recognise the values of this study, and would like to thank the editors for the positive comments.

1. While the whole paper becomes more readable and understandable in general, I still encounter difficulty in understanding those six propositions. After reading the propositions many times, I am still unsure what messages they are trying to deliver. I also read those paragraphs prior to the propositions carefully and cannot find clear connections between those paragraphs and the corresponding propositions. Could the authors pay more attention to this issue? Is it possible to make the propositions more specific and understandable rather than just putting different terms and jargons together? Also, need to make better connections between those paragraphs and the corresponding propositions to enable readers to make sense of why such propositions are proposed in this research.

Editors\#1.We would like to thank the editors for pointing this out. In the revision, we have re-visited our data to identify different organisational enablers that can facilitate the connections between the mechanisms and NPD performance. For example, after determining different cases prefer different searching modes (i.e., searching intensity and search proactiveness) to use social media for knowledge acquisition in the product ideation phase, we further explored the reasons and identified several organisational enablers that facilitate the emergence and effectiveness of different searching modes. More specifically, we identified that NPD projects with a high degree of social media searching activities were identified as always relying on a customer-focused organisational culture, while NPD projects with a high degree of social media searching proactivness were recognised as based on a diffused data-driven culture. In this way, the findings section is more consistent and propositions are more specific and testable. For the changes, please refer to section 4, on pages 13-23.

2. It's good to see a more commonly-agreed definition of social media is used in the revised paper, but I am still confused about how social media can be viewed as "co-developer" or "enduser" (Table 1). Social media, as defined in the revised paper, is just "a group of Internet-based applications" such as Facebook and Twitter. It is unclear how such an application can be a "co- 
developer" or "end-user". It should be the user of social media, rather than the social media per se, viewed as "co-developer" or "end-user". Moreover, I am also not connived by the matches between social media categories and NPD phases as indicated in Table 1. For example, social media as resources can be used for product $R \& D$ and also product testing and launch, not just for product ideation and design. A simple solution: drop those social media categories across Table 1 and section 2.1 to avoid unnecessary confusion and too strong arguments.

Editors\#2. We agree with the editors on this point. We have followed the suggestions and removed the social media categories from Table 1. Therefore, rather than identifying the key roles of social media, the revised version now focused on the use of social media in different NPD phases. Meanwhile, we have checked Section 2.1 thoroughly and changed the terms regarding the roles of social media (i.e., as resource, as co-developer, and as end-user) to avoid unnecessary confusion. For the changes, please refer to Section 2.1, on pages 4-7.

3. In the abstract, the findings section is very brief. I am not sure whether readers can understand what the authors find in this research after reading this section. Could the authors add one or two sentences to spell out this research's findings?

Editors\#3. Noted. In the revision, we have re-written the findings in the abstract. Particularly, the study identified three distinct types of mechanisms through organisational learning that extract the innovation potential inherent in social media. It further determined various organisational enablers that facilitate the connections between these mechanisms and NPD performance. Please refer to the abstract on page 1 .

4. When was this research conducted? Could the authors make it clear, at least in the methodology section?

Editors\#4. We appreciate the comments provided by the editors. In the revision, we have pointed out the time when the research was conducted. Particularly, starting from July 2017, a retrospective approach was applied to become familiar with the companies identified (Miller et al., 1997). Then, the main data collection took place between March 2018 and September 2019. Please refer to the changes in Section 3.2 (paragraph 3, on page 10) and Section 3.3 (paragraph 1, on page 11). 